\title{
Connecting Hazards Research and Geologic Maps to Risk Reduction*
}

\author{
Jeff Rubin, Emergency Manager \\ Tualatin Valley Fire \& Rescue \\ Oregon, USA
}




\section{Objectives}

- Describe Pacific Northwest (PNW) hazard profile

- Summarize hazard assessment process and needs

- Demonstrate applications of hazards research and geologic mapping to hazard assessment

- Apply research products to risk communication 


\section{Risk Reduction}

- Hazard vulnerability analyses (HVA)

- Land-use planning

- Building codes

- Structure/site improvements 


\section{Hazard vulnerability analysis (HVA)}

- What relevant hazards/threats are out there?

- How can they affect our ability to carry out our critical functions?

- History?

- Probability?

Extent?

Most likely vs. worst case?

- Where do we find this information? 


\section{Landslide mapping without LiDAR}

30-ft Digital Elevation Model

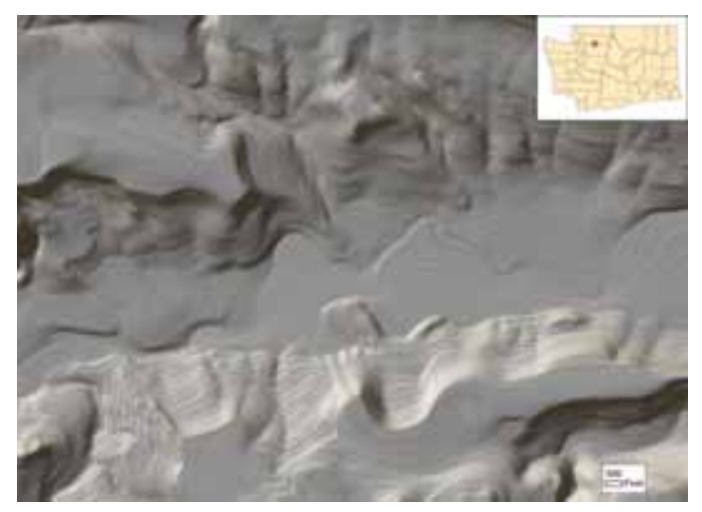

Air Photos

Topographic Maps
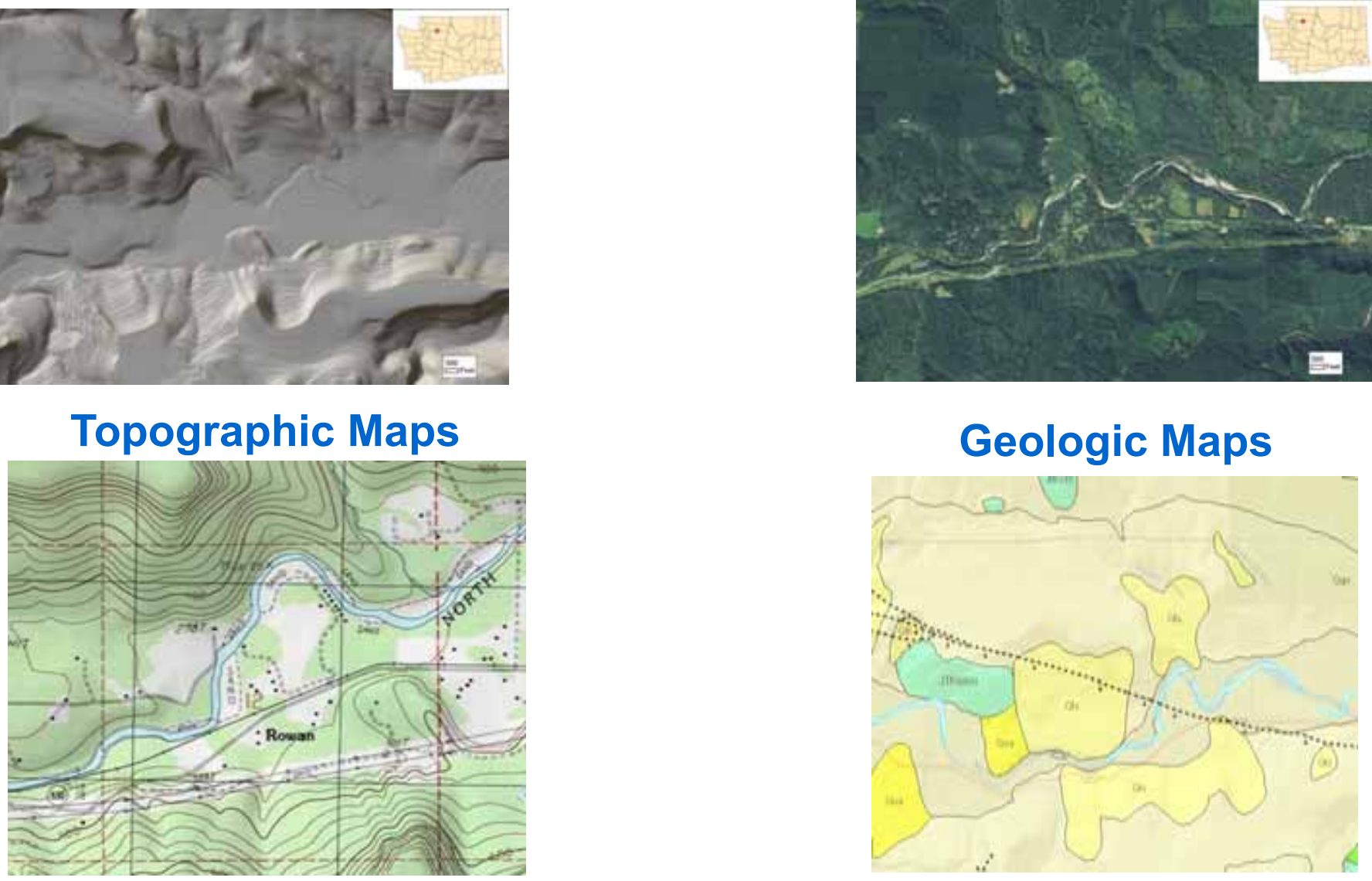

Geologic Maps

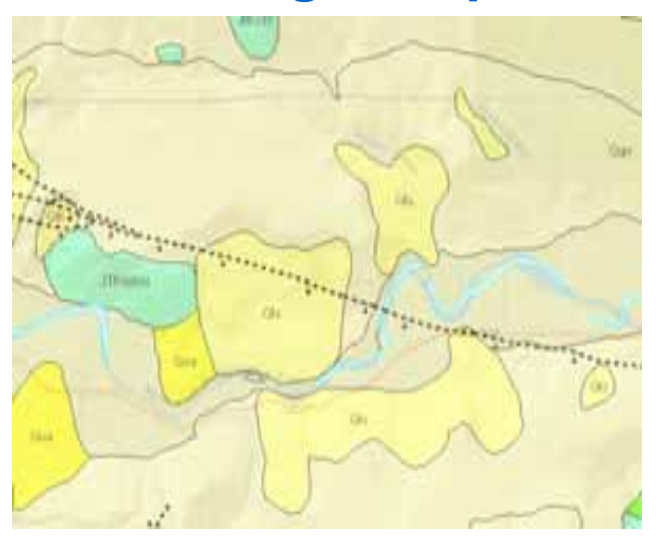

(DNR, WA Geological Survey, Dave Norman) 


\section{Oso/SR 530 landslide and surroundings}

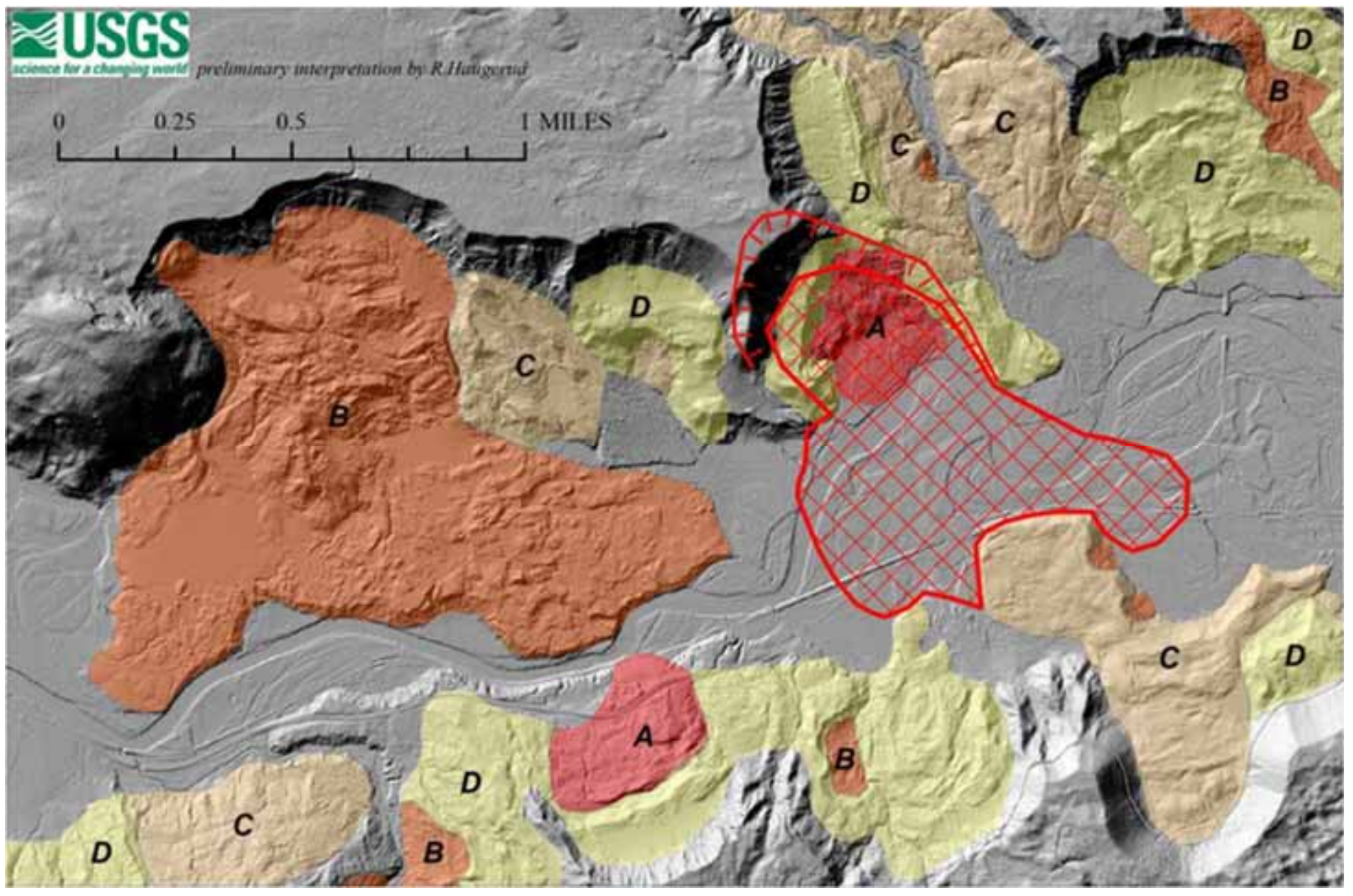




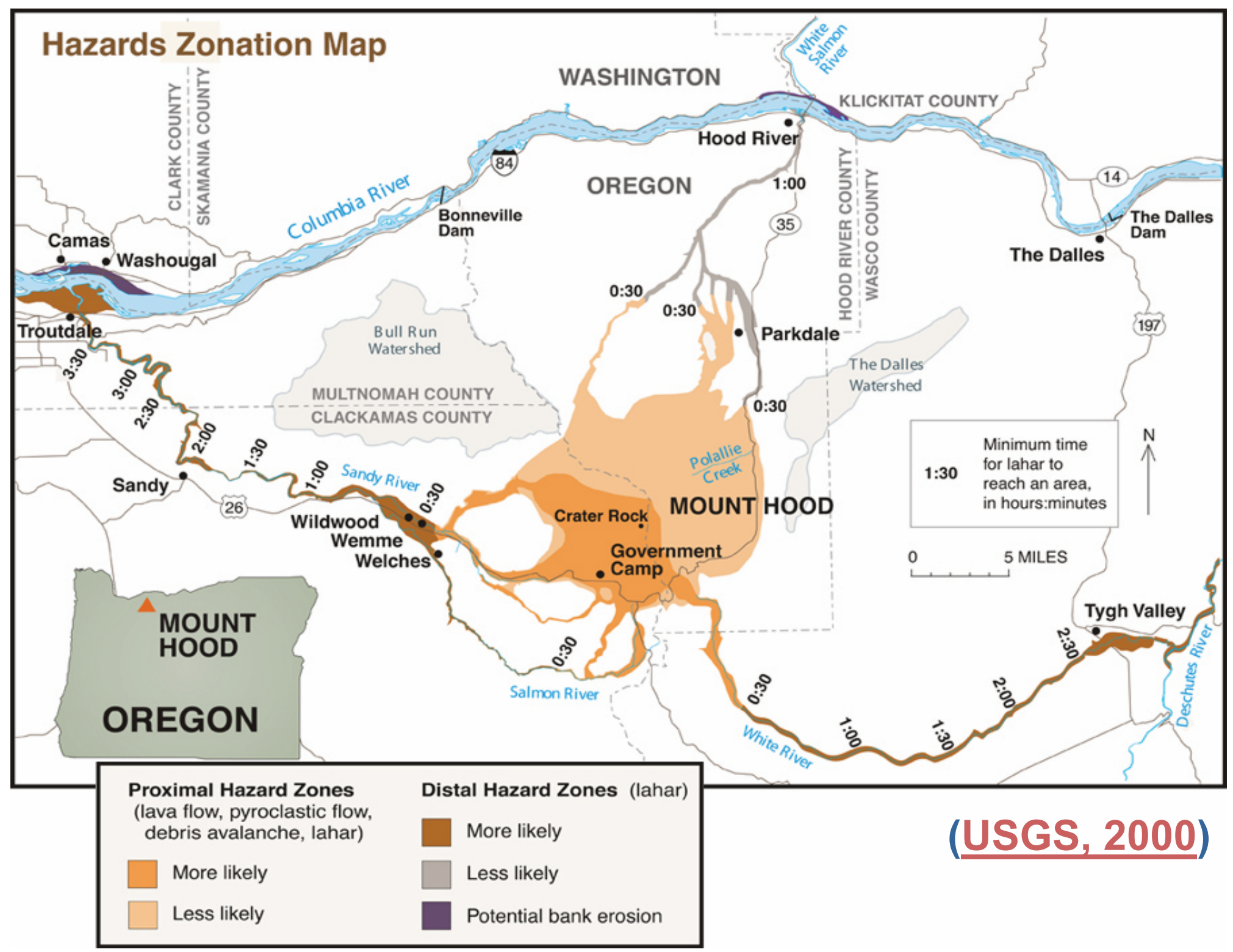




\section{Who's at risk? (USGS: Mathie \& Wood, 2013)}
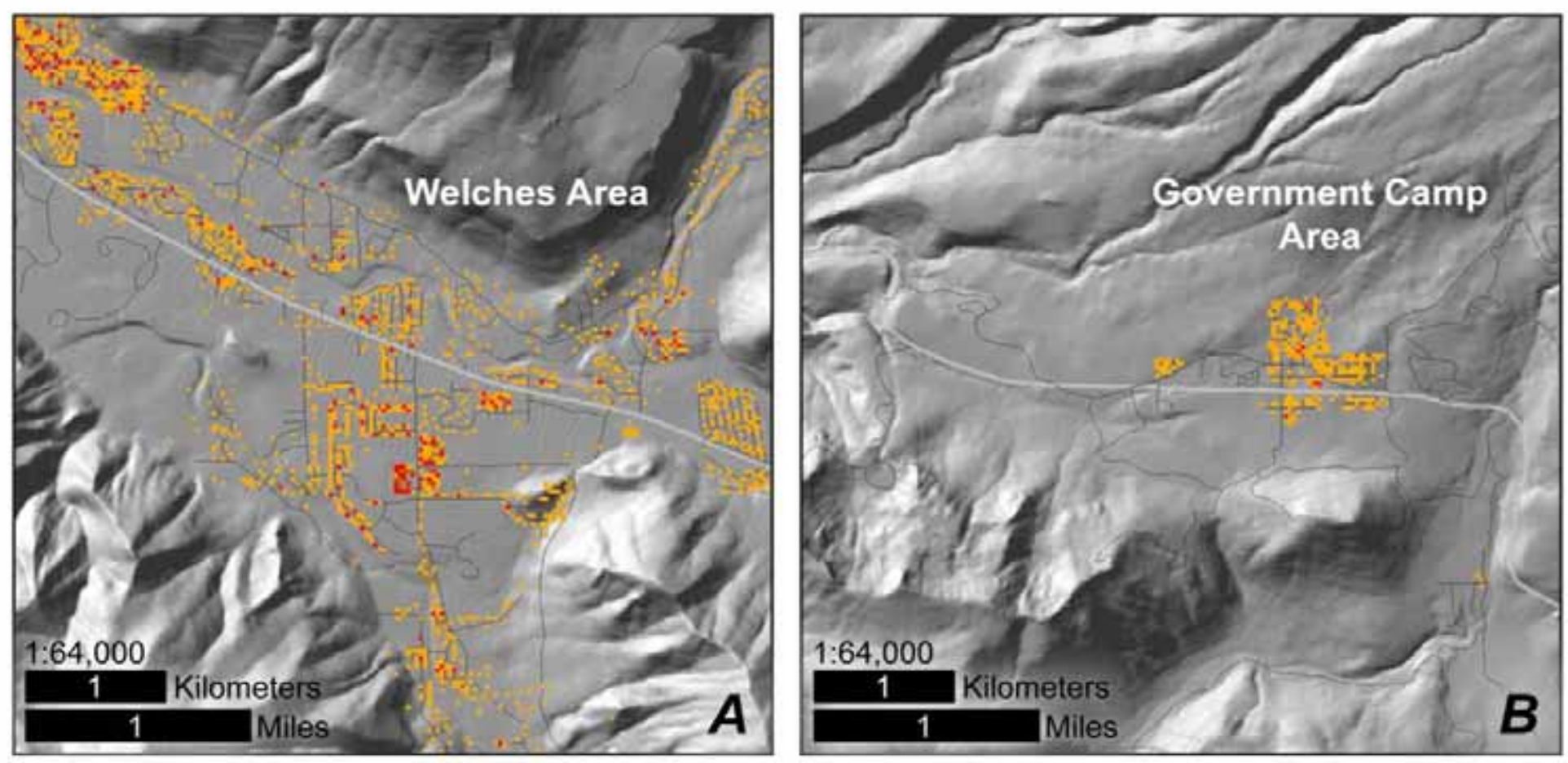

EXPLANATION

Residents per pixel

1 to 2

3 to 5

6 to 10

- Road Surface

$>10$

- Major Highway:

[\#) U.S. Route

(D) Oregon Route 


\section{Mt. Hood lahar property losses}

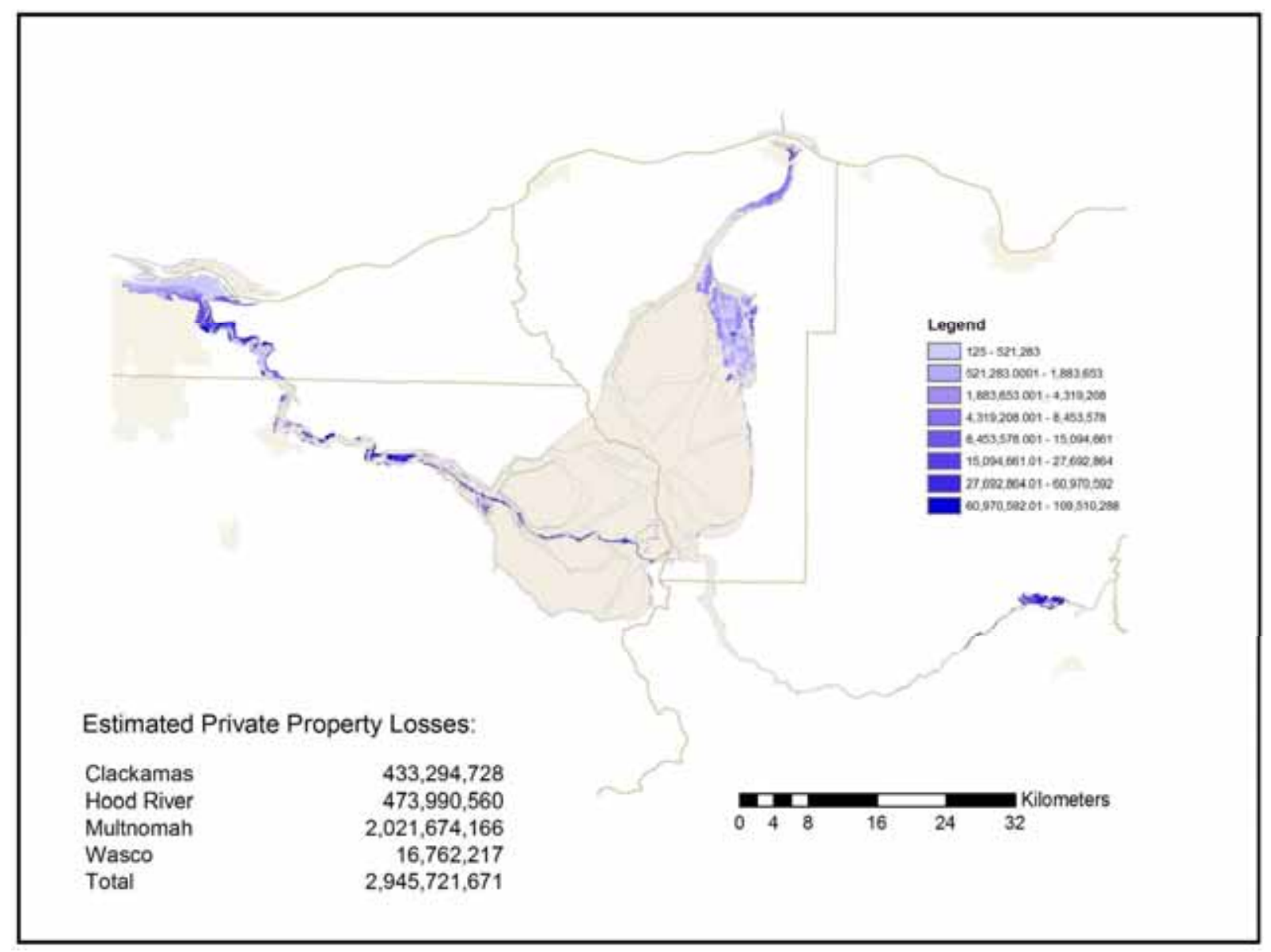

(PSU: Chappell, Dettlaff, Utz, 2009) 


\section{Seattle, Portland liquefaction maps}
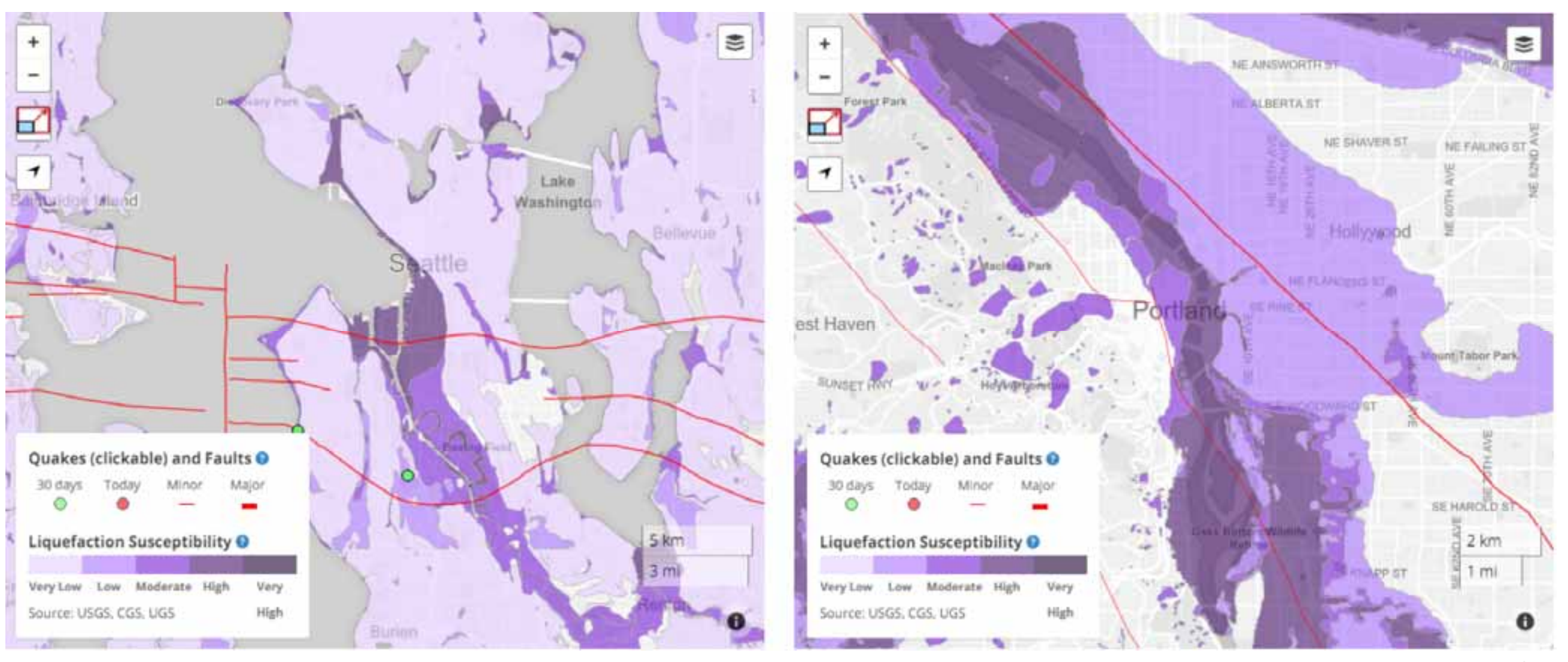

(Temblor, from USGS, state surveys) 


\section{$>$ Portland integrated hazards map}

The City of Portland

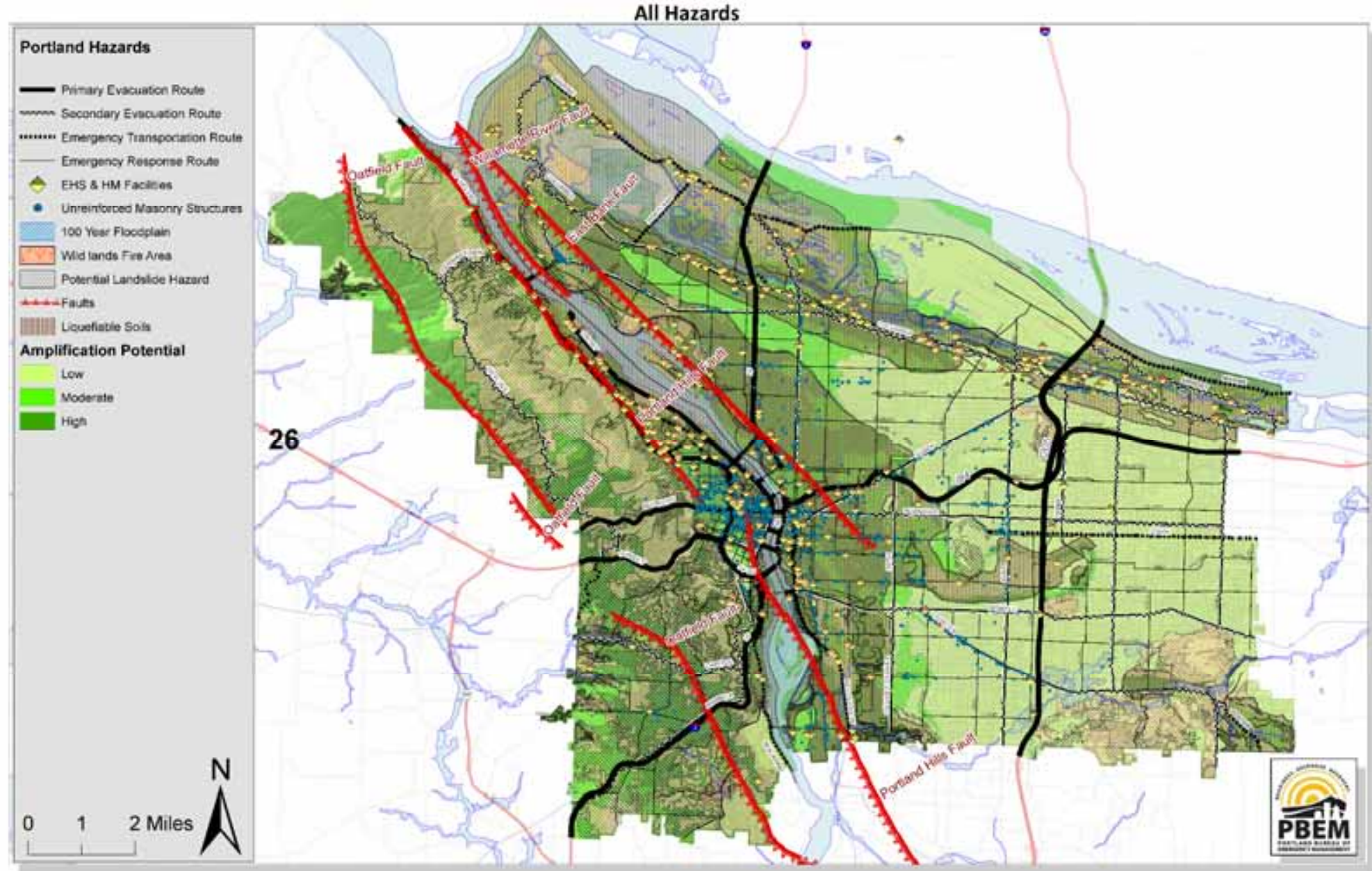




\section{Tsunami inundation map - Astoria (DOGAMI)}

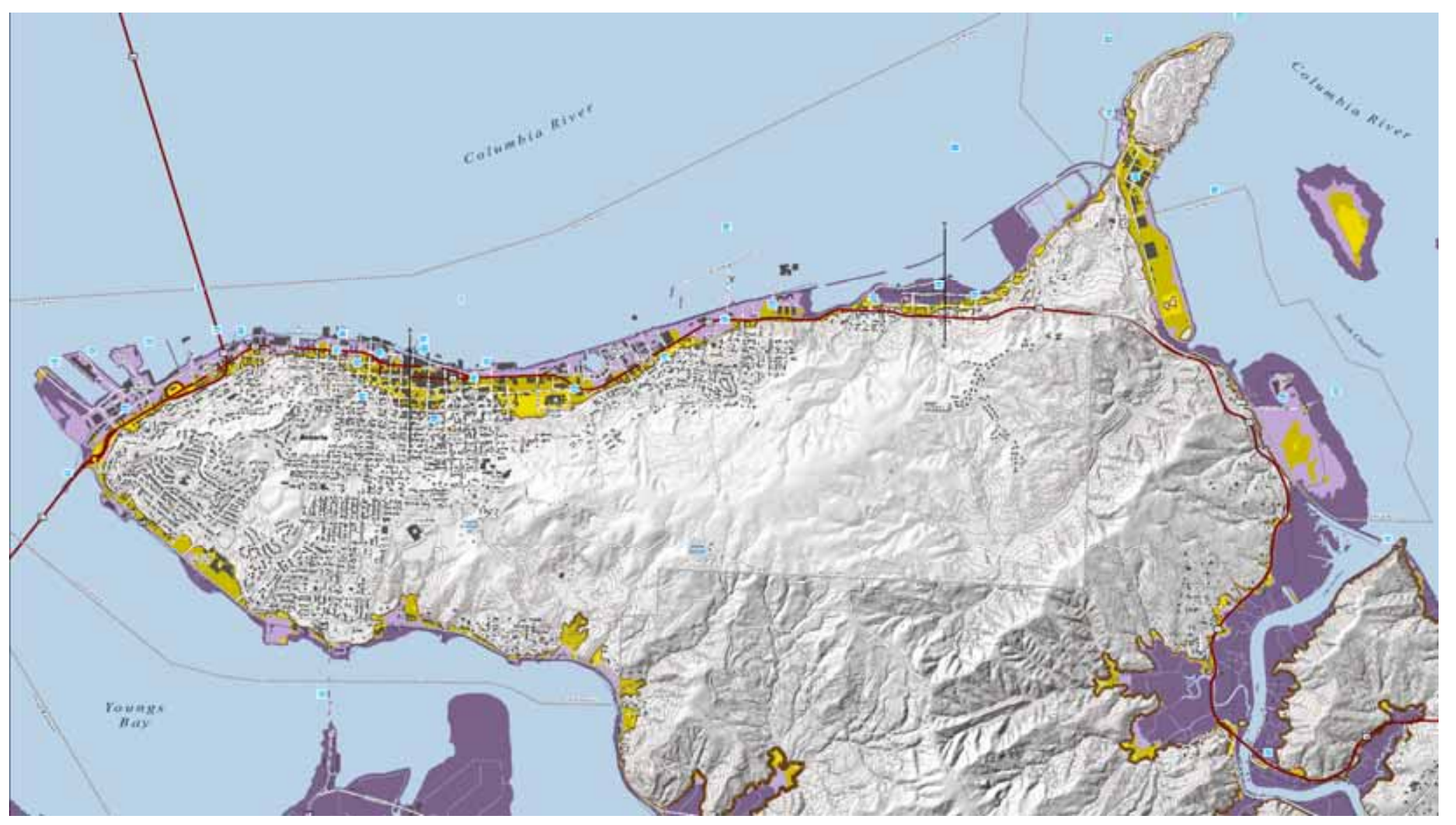




\section{Land-cover affects evacuation}

\section{(Wood \& Schmidtlein, 2012)}

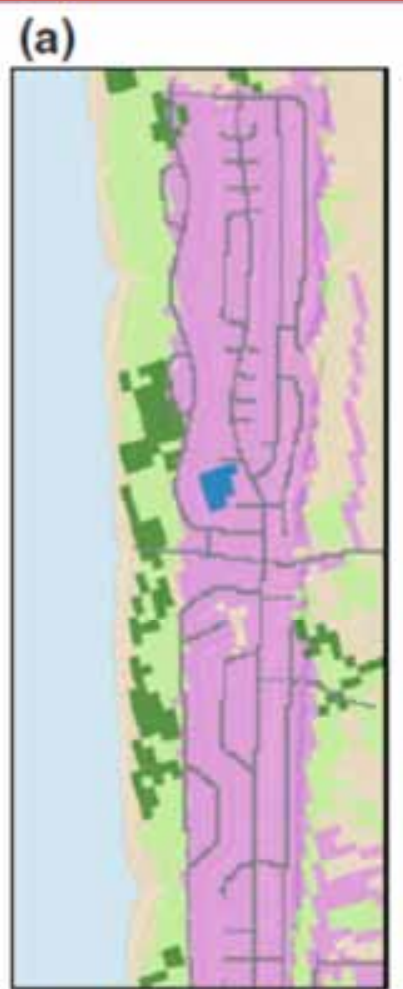

(b)

Land cover type (figures a and b)

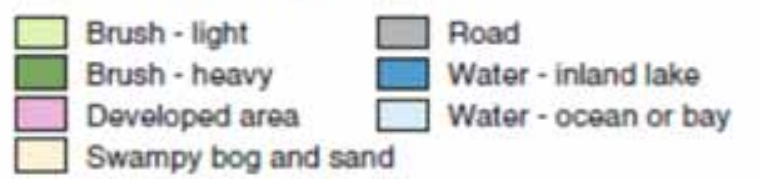

(c)

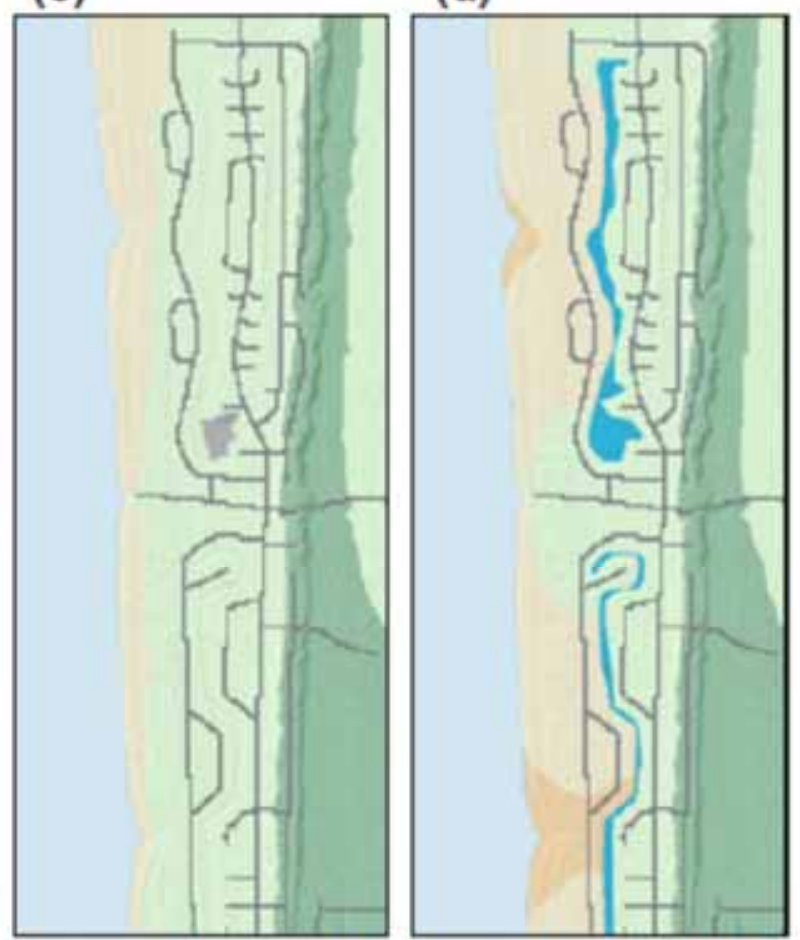

Travel time to safety in minutes (figures $\mathrm{c}$ and $\mathrm{d}$ )

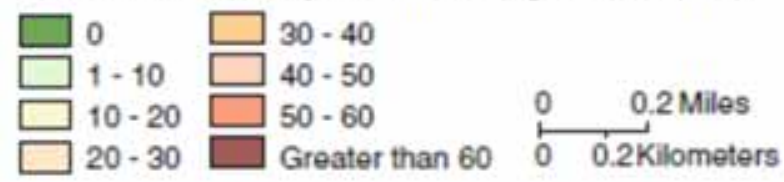




\section{Recovery}

- Policy input:

- Limit rebuilding in hazard-zones

- Build to better standards

- Develop more resilient infrastructure

- Incorporate more realistic planning assumptions 


\section{Communication}

- Are you part of the conversation?

- Pictures are great

- Opportunity to show nuance

What do you want to emphasize?

- How does that change with scenario and audience? 


\section{Communication}

Outcome $=$ Audience + Message + Medium

- Start from the left...

- Respect your audience

- Don't "dumb it down"

- Know your topic (and your limitations)

- Be consistent; communicate uncertainty

- Medium $\neq$ Message 


\section{Jeff Rubin, PhD, CEM}

Emergency Manager

Tualatin Valley Fire \& Rescue

@jeffrubin2

www.tvfr.com 